\title{
Investigation of MWCNT Reinforcement on the Strain Hardening Behavior of Ultrahigh Molecular Weight Polyethylene
}

\author{
Hassan Mahfuz, ${ }^{1}$ Mujibur R. Khan, ${ }^{2}$ Theodora Leventouri, ${ }^{3}$ and Efthymios Liarokapis ${ }^{4}$ \\ ${ }^{1}$ Department of Ocean and Mechanical Engineering, Florida Atlantic University, Boca Raton, FL 33431, USA \\ ${ }^{2}$ Mechanical Engineering Department, The University of Texas at El Paso, El Paso, TX 79968, USA \\ ${ }^{3}$ Physics Department, Florida Atlantic University, Boca Raton, FL 33431, USA \\ ${ }^{4}$ Department of Physics, National Technical University of Athens, Zografou Campus, 15780 Athens, Greece \\ Correspondence should be addressed to Hassan Mahfuz, hmahfuz@fau.edu
}

Received 14 September 2010; Revised 19 February 2011; Accepted 20 February 2011

Academic Editor: Valery Khabashesku

Copyright ( $) 2011$ Hassan Mahfuz et al. This is an open access article distributed under the Creative Commons Attribution License, which permits unrestricted use, distribution, and reproduction in any medium, provided the original work is properly cited.

\begin{abstract}
We have investigated strain hardening behavior of ultrahigh molecular weight polyethylene (UHMWPE) reinforced with $2.0 \mathrm{wt} \%$ loading of multiwalled carbon nanotubes (MWCNTs). A solution spinning process was used to produce neat and MWCNTreinforced filaments of UHMWPE. Tensile tests of filaments showed $62 \%$ and $114 \%$ improvement in strength and modulus, respectively. Strain hardening tests on filaments revealed spectacular contribution by MWCNTs in enhancing strength and modulus by more than one order of magnitude. SEM micrographs showed sufficient coating of nanotube surface with the polymer that promoted interface adhesion. This intimate interfacial interaction enforced alignment of nanotubes during repeated loadingunloading sequences and allowed effective load transfer to nanotubes. Close interaction between UHMWPE and nanotubes was further evidenced by Raman spectral distribution as a positive shift in the D-band suggesting compressive stress on nanotubes by lateral compression of polymer. Nanotubes thus deformed induced the desired strain hardening ability in the UHMWPE filament. Differential scanning calorimetry (DSC) tests indicated around 15\% increase in crystallinity after strain hardeningwhich together with nanotube alignment resulted in such dramatic improvement in properties.
\end{abstract}

\section{Introduction}

UHMWPE is regarded as one of the most promising high performance fibers because of its low density, excellent strength to weight ratio, and outstanding impact property. Applications of this fiber have significantly increased in recent years in defense industries in manufacturing light weight ballistic plates, bulletproof helmet and vest, and shielding for armored vehicles. It is also used in composite materials for aviation and space flights, ropes for navy vessels, and in sports equipments. Such synthetic fibers typically need to have adequate tensile strength, high modulus, and long-term structural stability to satisfy a wide range of performance criteria. Its molecular chain can consist of as many as 200000 ethylene $\left(-\mathrm{CH}_{2}-\right)$ repeat units forming a linear structure with a molecular weight of 3 to 6 million $\mathrm{g} /$ mole $[1,2]$.
In recent years it has been convincingly shown that inclusion of nanotubes can significantly influence the tensile properties of thermoplastic polymers including UHMWPE. $[3,4]$. At identical draw ratio $(\sim 30)$ the strength and modulus of UHMWPE can be increased by $19 \%$ and $12 \%$, respectively when, reinforced with $5 \mathrm{wt} \%$ of MWCNTs [5]. It has also been revealed that the ability of the polymer fibrils to undergo molecular orientation through strain hardening can greatly enhance the strength and stability of the craze structure $[6,7]$. Strain hardening in polymers is thought to be mainly due to the effects of orientation. Since the anisotropic nature of the chemical bonding in UHMWPE can cause a highly oriented polymer, strength and stiffness are expected to increase through strain hardening sequences. Moreover, increased strain hardening effect has been reported with increasing crystallinity in polyethylene due to the contribution of network density of chains 


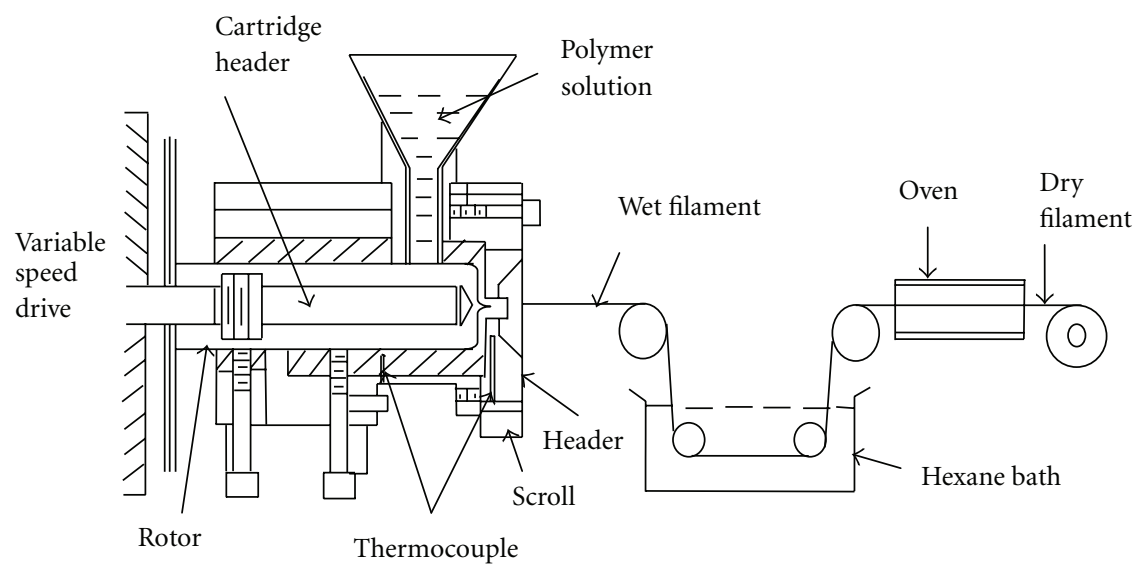

FIGURE 1: Schematic representation of filament extrusion.

anchored in adjacent crystals [8]. Since UHMWPE has higher chain entanglement, it is likely that strain hardening effect will be more. It has also been reported that inclusion of CNTs can further increase polymers hardening. As reported in reference [9], PA-6 composites reinforced with MWCNTs have exhibited more postyield hardening characteristic than neat PA6. Increased strain hardening effects were also observed at large strain in polyethylene when reinforced with MWCNTs. It was reported that MWCNTs acted as tie molecules to induce strain hardening effects [5].

MWCNTs have exceptionally high strength and modulus. Their structural defect sites are ideal nucleation sites and are favorable for strong interaction with the surrounding polymers [10]. Moreover, strain hardening sequences of repeated loading and unloading are effective mechanisms to enhance tensile properties by uniaxially arranging the polymer chains and increasing the crystallinity. In addition, strain hardening process can also cause improved alignment of embedded nanotubes along the filament length. Such alignment will be useful in transferring load from polymer chains to nanotubes.

UHMWPE filaments cannot be produced using conventional extrusion process because of its high melt viscosity. Strong Weissenberg effects [11] have to be overcome during the solution preparation and extrusion phases. Gel-spinning process has been used by many researchers to produce UHMWPE filaments [11-14]. In this process polymer is dissolved in a solvent and spun through a spinneret. The polymer precursor is then drawn at elevated temperatures to a very high draw ratio $(\sim 50)$. However, there is a significant change in the process when CNTs are reinforced. Nanotubes tend to agglomerate during solvent evaporation and can lead to inhomogeneous distribution [15]. In an attempt to remedy these difficulties, a combination of sonication for nanotubes dispersion, melt mixing, and extrusion has been used in the current investigation. Details for filament fabrication, strain hardening experiments, and morphological characterizations are described.

\section{Synthesis and Fabrication of Filament}

Commercial grade UHMWPE powder, paraffin oil, and antioxidant 2, 6-di-t-butyl, 4-methylcresol were procured from Sigma Aldrich Co. (6000 North Teutonia Avenue Milwaukee, Wis). The average density, melting point and molecular weight of UHMWPE were $0.94 \mathrm{~g} / \mathrm{cm}^{3}, 138^{\circ} \mathrm{C}$ and $3 \times$ $10^{6} \mathrm{~g} / \mathrm{mole}$, respectively. The MWCNTs were also obtained from Sigma Aldrich Co. as received nanotubes were 110$170 \mathrm{~nm}$ in diameter and approximately $4-9 \mu \mathrm{m}$ long. MWCNTs were not functionalized with any chemical group. Filaments were fabricated using a Laboratory Mixing Extruder (LME) as shown in Figure 1. The extrusion apparatus included a hexane bath, an oven, and a filament take-up system. A VCX 500 ultrasonic processor and a homogenizer (VDI 25) were used for dispersion of nanotubes. Two types of filaments were produced; (i) neat UHMWPE and (ii) UHMWPE with $2 \mathrm{wt} \%$ MWCNT.

In the synthesis of filaments, $5.0 \mathrm{wt} \%$ of UHMWPE and $0.5 \mathrm{wt} \%$ of anti-oxidant were first mixed with $94.5 \mathrm{wt} \%$ of paraffin oil using the homogenizer. Anti-oxidant was used to prevent oxidative degradation of the polyethylene and to stabilize the solution. After mixing for about 15 minutes, the admixture was poured into LME hopper and passed through the annular zone of the extruder. The solution was then heated to $140^{\circ} \mathrm{C}$ using the turning rotor. The rotor allowed mechanical stirring as well as heat conduction to the melt. At this stage the solution turned into a viscous gel and as the rotation continued, it flowed to the outlet dies and exited through the orifice. The orifice diameter was $3 \mathrm{~mm}$. The speed of the turning rotor was kept low to avoid excessive shear in the annular zone. After extrusion, filaments were rinsed through a hexane bath, dried in an oven, and drawn into a take-up spindle. The speed in the take-up system was adjusted to control the draw ratio. The rotor and header temperatures of the extruder were set at $140^{\circ} \mathrm{C}$ and $150^{\circ} \mathrm{C}$, respectively. The oven temperature was set at $100^{\circ} \mathrm{C}$ in order to evaporate the solvent. Cut filaments strands were again heated in a separate oven to 
Table 1: Tensile Test Data.

\begin{tabular}{lcccc}
\hline Type & Yield Strength $(\mathrm{MPa})$ & Ultimate Strength $(\mathrm{MPa})$ & Modulus $(\mathrm{MPa})$ & Fracture Strain $(\%)$ \\
\hline Neat UHMWPE & $20 \pm 5$ & $61 \pm 6$ & $238 \pm 17$ & $131 \pm 19$ \\
UHMWPE-MWCNT & $80 \pm 10$ & $99 \pm 11$ & $510 \pm 28$ & $90 \pm 10$ \\
\hline
\end{tabular}

$60-70^{\circ} \mathrm{C}$ for a prolonged period of time ( $\left.\sim 48 \mathrm{hrs}\right)$. For the second category of filaments, $2.0 \mathrm{wt} \%$ of MWCNTs were first dispersed into paraffin oil using sonication for about two hours. Sonication was performed at $60 \mathrm{~Hz}$ and at $45 \%$ intensity. UHMWPE and anti-oxidant were then mixed with this solution using homogenizer and poured into LME. The rest of the procedures were identical as before.

It is to be noted here that we came up with $2.0 \mathrm{wt} \%$ concentration of MWCNTs after several iterations. When the concentration of MWCNTs was above $2.0 \mathrm{wt} \%$, flow viscosity increased and continuous production of filament was not possible without applying excessive shear force by the turning rotor. Application of high shear force during the extrusion process broke the polymer chains and restricted filament production. On the other hand, low concentration $(0.5 \mathrm{wt}$ $\%)$ of CNTs did not have any detrimental effects on the processability, but showed minimal impact on the properties.

In recent years, we have dealt with similar polyethylenebased systems and published our results $[16,17]$. In addition, our past studies $[3,4,18,19]$ with reinforcement of nanoparticles/nanotubes in thermoplastic polymers also suggest that concentrations of CNTs usually vary between $1-2 \mathrm{wt} \%$, especially with the melt extrusion method that we have used. In reference [5], Ruan et el. have investigated UHMWPE with $5.0 \mathrm{wt} \%$ MWCNT loading. Higher concentration in their case was possible since the synthesis method was different. Once we found a workable concentration of MWCNTs at $2.0 \mathrm{wt} \%$, and a good improvement in properties was achieved, we concentrated on evaluating the strain hardening behavior.

\section{Tensile and Strain Hardening Tests}

Tensile tests of individual filament from each category of samples were conducted using a Zwick-Roell material testing machine according to ASTM D3379-75. Diameters of the filaments were measured using a Scanning Electron Microscope. Tests were run under displacement control at a constant crosshead speed of $2 \mathrm{~mm} / \mathrm{min}$ using a $20 \mathrm{~N}$ load cell. A gage length of $30 \mathrm{~mm}$ was used. About 10 individual filaments were tested in each category. To visualize the hysteresis effect of loading, samples were strain-hardened through a series of loading and unloading cycles using the same material testing machine. Strain hardening tests were simple tension tests in which samples were first loaded up to a point slightly beyond the yield point and then unloaded to zero load level. This completed the first loop. In the next step, samples were loaded again to a higher point, incremented by both load and deflection followed by another unloading. This formed the second loop. Such loading and unloading continued until the fiber failed. A set of hysteresis curves for

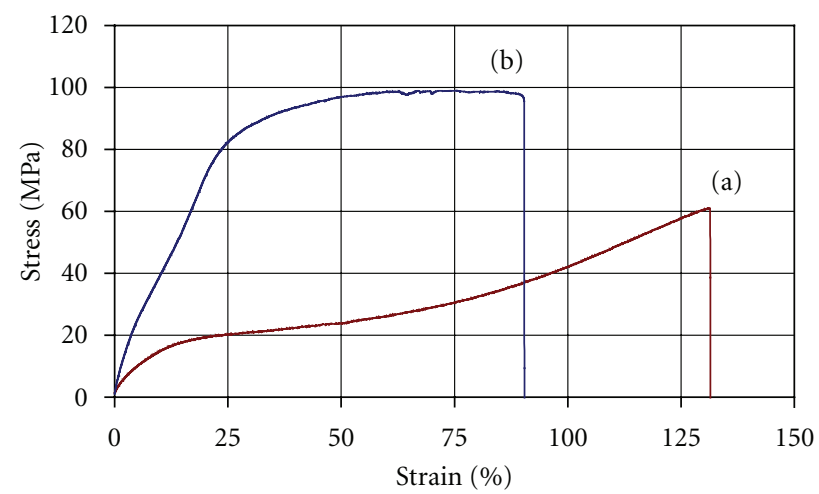

Figure 2: Tensile stress-strain curves of (a) Neat UHMWPE (b) UHMWPE-MWCNT.

each category of filaments were generated in this manner. True strains were calculated [20], and maximum true-stress versus true-strain was plotted in logarithmic scale. The plot depicted $\sigma=K \widetilde{\varepsilon}^{n}$, where $\sigma$ was the true stress, $\widetilde{\varepsilon}$ was true strain, $n$ was strain-hardening exponent, and $K$ was strength coefficient. Values of $n$ and $K$ were tabulated.

\section{Results and Discussions}

4.1. Individual Filament Test. Representative stress-strain diagrams and the data from tensile tests are shown in Figure 2 and Table 1. It was observed that with the infusion of MWCNTs the Young's modulus and ultimate tensile strength of neat UHMWPE increased by $114 \%$ and $62 \%$, respectively. It was also noticed that yield strength $(0.2 \%$ offset $)$ increased by almost $300 \%$ with the addition of MWCNTs. It is seen that yielding of both categories of fiber is taking place at about $24 \%$ strain. However, strain to fracture reduced from $131 \%$ to $90 \%$.

A comparison of stress-strain response (Figure 2) of the current materials system with those of references [35 ] is presented to put things into proper perspective. Comparing with [4], it is observed that although the two systems are different, reduction in fracture strain in the present case is much smaller-from $131 \%$ to $90 \%$. On the other hand, in [4], which is a polyamide system, the reduction in fracture strain was from $290 \%$ to $25 \%$ with the inclusion of MWCNTs. This suggests that the chance of interface slippage between MWCNTs and polymer is greater in the current system of polyethylene. Existence of such slippage at the interface would make UHMWPE-MWCNT system ideal for strain hardening studies. Less reduction in fracture strain is also evident in reference [3] which 


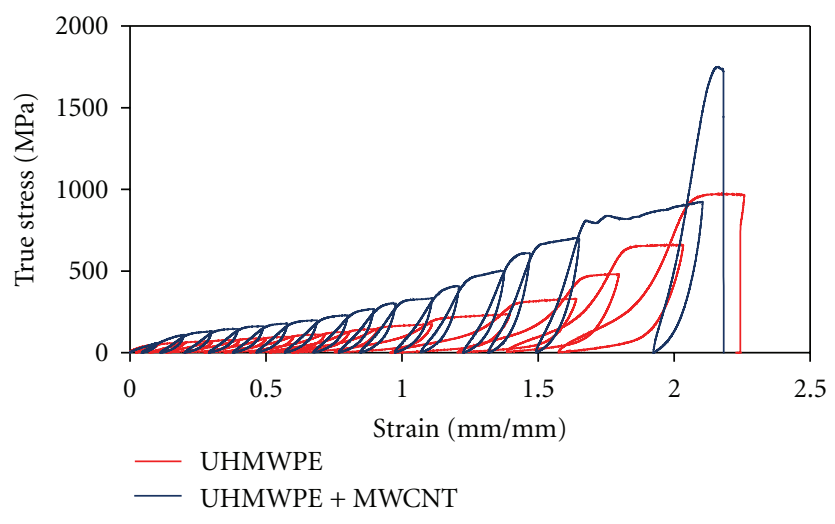

FIGURE 3: Cyclic true stress-strain hysteresis curves for neat and nanophased UHMWPE filament.

is again a polyethylene-based system-a linear low density polyethylene (LLDPE) reinforced with CNTs. It was observed that with $2.0 \mathrm{wt} \%$ CNT reinforcement, strength and modulus increased modestly by $34 \%$ and $37 \%$, respectively.

Reduction in fracture strain was also low; from $42 \%$ to $12 \%$ - pointing to the fact that reinforcement of CNTs in polyethylene-based system induces some sliding at the interface causing less reduction in fracture strain - which was clearly not the case with the amide system [4].

We also compared our stress-strain response with those of reference [5] which is an identical system like ours. Concentration of MWCNTs was however, at $5.0 \mathrm{wt} \%$ in reference [5]. The method of fiber processing was also different. In reference [5], fibers were produced in three stages and were named as follows: gel fiber, precursory fiber, and highly oriented fibers. Tests were conducted on the latter two categories only. Our fibers would fit somewhere between gel and precursory categories before strain hardening, and probably close to highly oriented fibers after strain hardening (although we did not have any heating involved during strain hardening). Stress-strain response of Figure 2 compares reasonably well with that of precursory fiber, but percentage improvement in strength and modulus in our case is much higher. Highly oriented fibers of reference [5] can be compared with our strain hardened fibers. In both cases, strength and modulus are significantly higher than the previous categories. It is also observed that absolute values of strength and modulus are higher in reference [5], but percentage gain with respect to the neat system is much larger in our case.

The extremely high stiffness of MWCNTs $(\sim 1 \mathrm{TPa})$ will certainly contribute to the bulk stiffness of composite following the rule of mixture. Although the volume fraction of the MWCNTs is small, its contribution to the composite stiffness is indeed substantial. Large increase in strength suggested a strong affinity that existed between the polymer and the nanotubes. Multiple graphene sheets with their circular curvature and pentagonal defects are highly favorable to develop strong interaction between nanotubes and polyethylene chains [21]. Due to such interactions, tubes can be coated with a polymeric layer through which stress can be

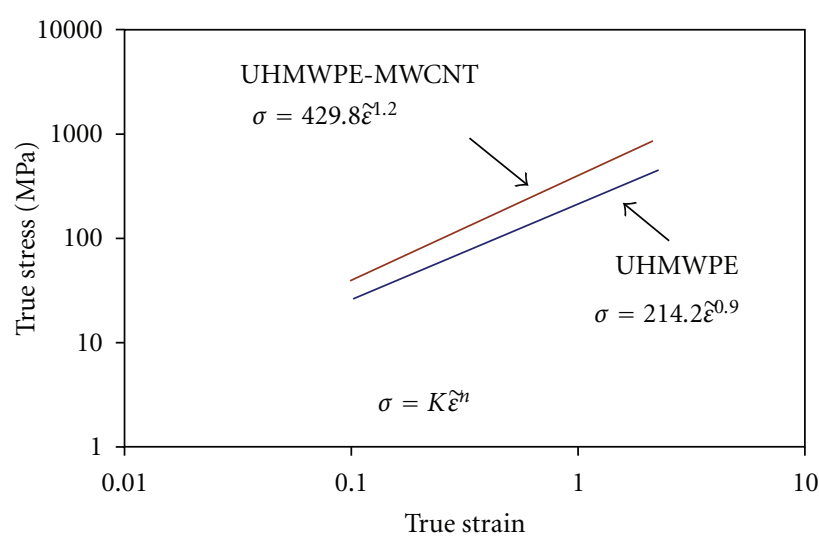

FIGURE 4: Log-log plot of true stress-true strain.

transferred from the matrix to nanotubes. These MWCNTs may also act as pseudo taut tie molecules at large strains to induce strain hardening effects [5]. The strength and modulus of the filaments can be further increased through such repeated loading and unloading sequences as discussed in the following section.

4.2. Strain Hardening. True stress versus strain curves generated from the strain hardening tests are shown in Figure 3. It is seen in Figure 3 that more than 200\% strain was possible for both categories of samples. At such large strain, both strength and modulus were also higher. Strength and modulus for UHMWPE samples increased to 0.97 and $3.9 \mathrm{GPa}$, respectively. This is a phenomenal increase from 61 and $238 \mathrm{MPa}$ shown in Table 1. Enhancement in properties is more than one order higher. When nanotubes were reinforced, improvement in strength and modulus was even better as evidenced in Table 2. Strength and modulus increased roughly to 2 and $10 \mathrm{GPa}$. To assess strain hardening behavior further, true stress versus true strain curves are shown in logarithmic scale Figure 4. Strain hardening exponent, $n$ and strength coefficient, $K$ for both categories of filaments are shown in Table 2. Exponent $n$ is a measure of the increase in strength of a material due to plastic deformation. It is an important parameter reflecting material's hardening ability and regarded as a measure of the rate of strain hardening. Higher value of $n$ in UHMWPE-MWCNT samples suggests larger degrees of strengthening for a given strain. The strength coefficient, $K$, determines the magnitude of true stress in the large strain region. Value of $K$ is almost doubled in MWCNT reinforced samples. It is therefore clear that MWCNT induces strain hardening capability in UHMWPE filaments. During the strain hardening process, due to the applied strain energy, the chains from the lamellae can partially unfold and break into small crystallites forming a more oriented microfibril structure [22-24]. Strain hardening effect at high draw ratio is also a consequence of the large surface to volume ratio of the microfibrils, which provide strong resistance to their shearing displacement [25]. It is expected that the 


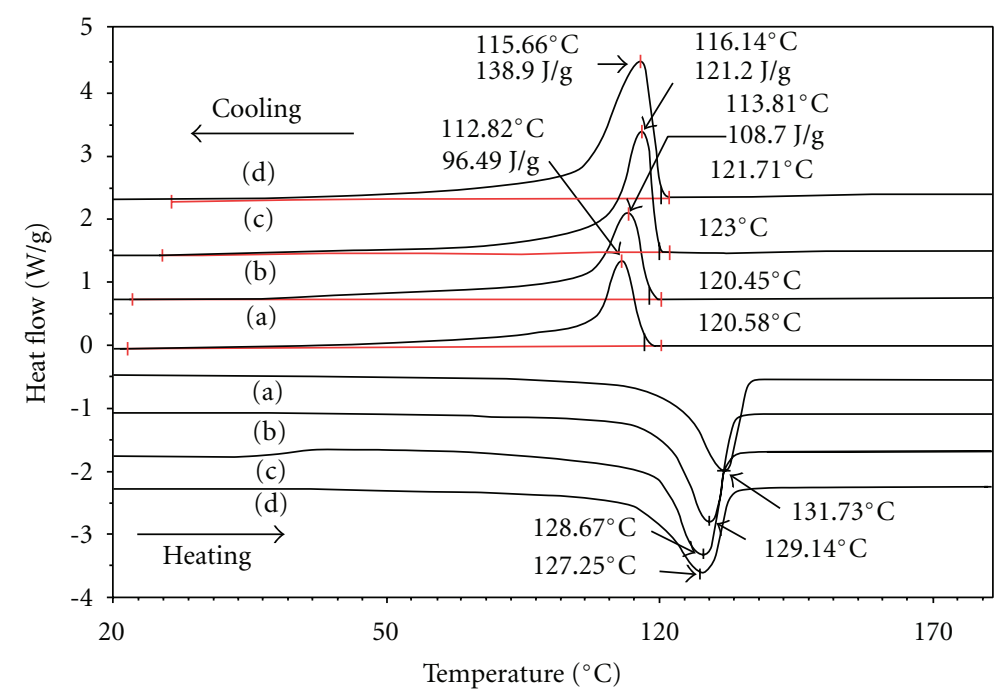

FIGURE 5: DSC heating and cooling curves of (a) Neat UHMWPE (b) Strain hardened UHMWPE (c) UHMWPE-MWCNT (d) Strain hardened UHMWPE-MWCNT.

TABLE 2: Data after strain hardening tests.

\begin{tabular}{lcccc}
\hline Type & $\begin{array}{c}\text { Strength } \\
(\mathrm{GPa})\end{array}$ & $\begin{array}{c}\text { Modulus } \\
(\mathrm{GPa})\end{array}$ & $n$ & $K(\mathrm{MPa})$ \\
\hline UHMWPE & $0.97 \pm 0.03$ & $3.9 \pm 0.2$ & 0.91 & 214 \\
$\begin{array}{l}\text { UHMWPE- } \\
\text { MWCNT }\end{array}$ & $1.9 \pm 0.08$ & $10.3 \pm 0.3$ & 1.15 & 430 \\
\hline
\end{tabular}

presence of MWCNTs with their high specific surface area can further increase this surface to volume ratio and provide more strain hardening effect to the composite. It has been reported recently that at intermediate strains, MWCNTs can act as slippage sites allowing the matrix to deform without significant bond stretching [26]. Moreover, polymer deformation can also affect nanotubes orientation and can cause strain-induced crystallinity at increasing strain. Oriented nanotubes and increased crystallinity will contribute to enhancement of tensile properties. These phenomena were further investigated through DSC and SEM analysis.

4.3. DSC (Differential Scanning Calorimetry) Tests. DSC Ramp tests for both heating and cooling were carried out under inert atmosphere. Regular as well as strain hardened samples were tested. Heating and cooling rate was $10^{\circ} \mathrm{C} / \mathrm{min}$ for all samples. Tests were performed in a TA Q10 DSC apparatus with about $5 \mathrm{mg}$ samples. Percent crystallinity, melting temperature $\left(T_{m}\right)$, crystallization onset temperature $\left(T_{o}\right)$, and peak crystallization temperature $\left(T_{p}\right)$ were recorded from the DSC curves as shown in Figure 5. Percent crystallinity was determined from the area under the cooling exotherms and heat of fusion for polyethylene. Crystallization time was also recorded and rate of crystallization was calculated. DSC test results are shown in Table 3. There was a moderate increase in crystallinity from $33.5 \%$ to $42.1 \%$ when MWCNTs were added to UHMWPE. We also noticed an increase in crystallinity with strain hardened samples. As seen in Table 3, crystallinity increased to $48.2 \%$ with strain hardened UHMWPE-MWCNT samples. Increase in the rate of crystallization also showed a similar trend. MWCNTs can act as nucleation agents for crystal growth around the nanotubes. As such, tubes can be coated with a layer of crystalline polymer. An interfacial region can therefore develop [27]. Formation of such interfacial regions helped strain-induced crystallization after strain hardening as evidenced in Table 3. Slight reduction in dT (difference between onset and peak crystallization temperatures) is shown with strain hardened samples. This is an indication of narrow lamellar distribution inside the material [28]. Formation of such narrow lamellar distribution is quite possible during extension and retraction sequences of strain hardening. It is also seen in Table 3 that melting temperature decreased for both nanophased and strain hardened samples. Reduction in melting temperature by nanoscaled materials is consistent to what was reported earlier $[29,30]$.

4.4. SEM Studies. SEM analyses were carried out in a D8303 Quanta 200 scanning electron microscope and micrographs are shown in Figure 6. Figures 6(a) and 6(b) show SEM images of UHMWPE filaments before and after strain hardening. The images illustrate a comparative view of the polymer fibrils arrangement. The arrows in the figures indicate filament axis and loading direction during strain hardening tests. Some degree of polymer chain alignment is seen in Figure 6(a). This partial alignment has happened during the extrusion and stretching phase. On the other hand, Figure 6(b) shows much improved orientation that was achieved through strain hardening cycles. This suggests that molecular rearrangements have indeed taken place during loading and unloading operations. Since relaxation process is restricted in the solid state, chains are trapped 


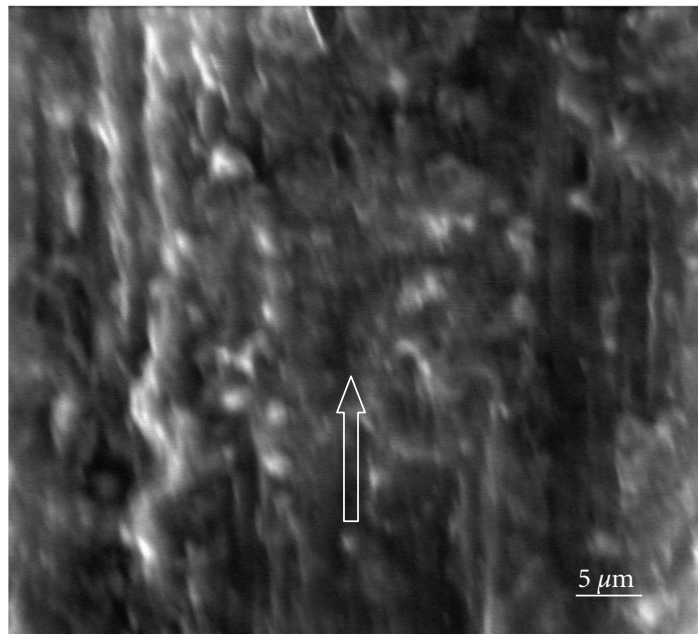

(a)

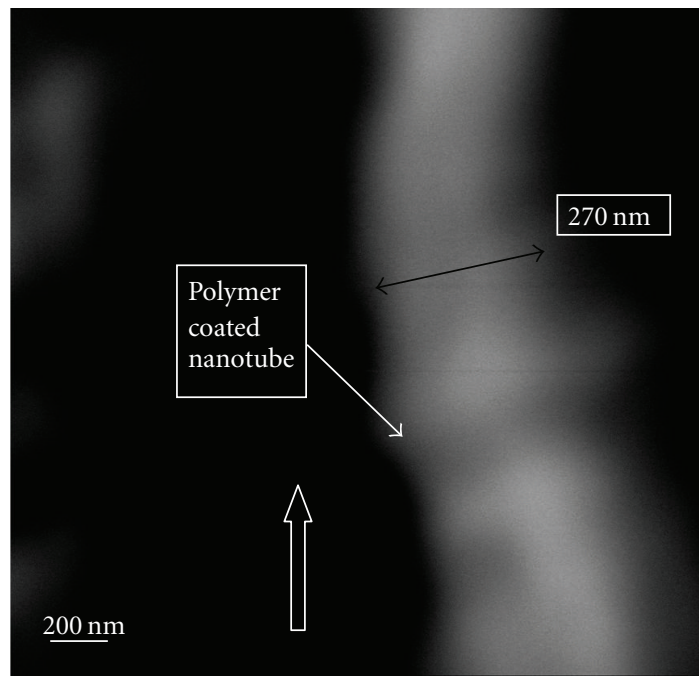

(c)

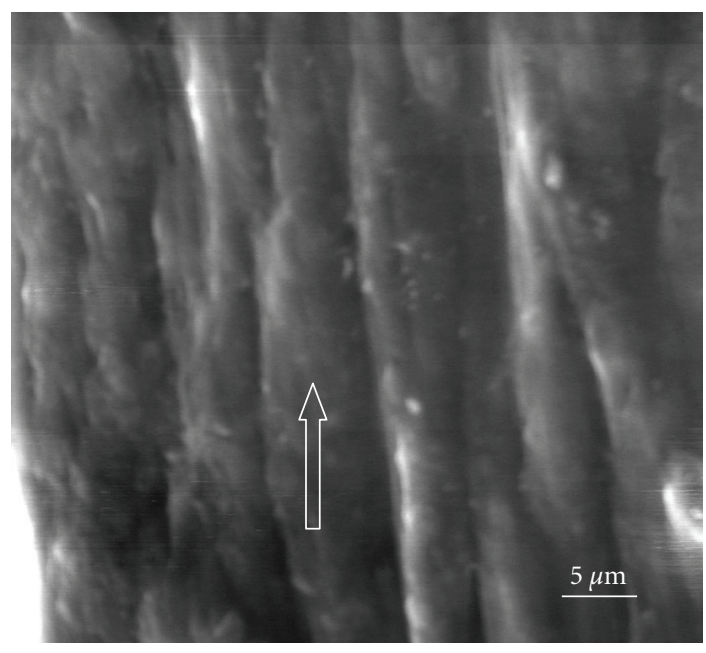

(b)

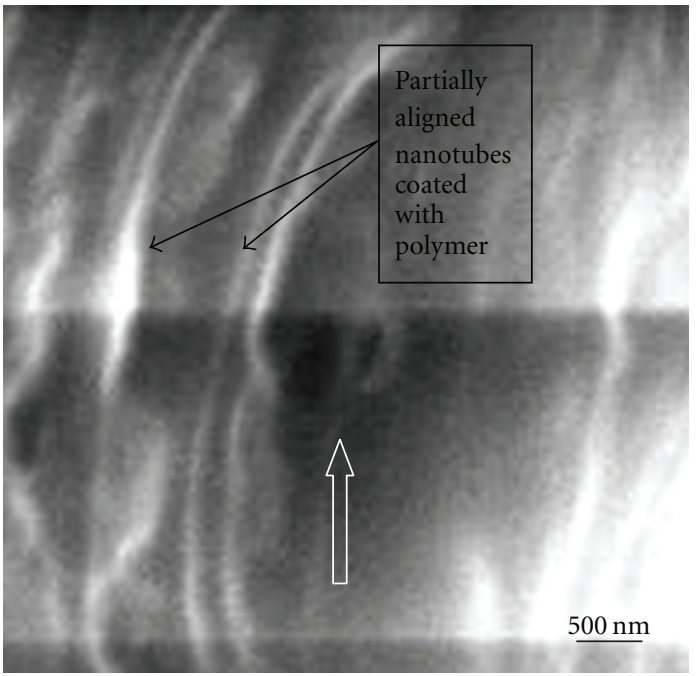

(d)

FIGURE 6: SEM micrographs of (a) neat UHMWPE, (b) strain hardened UHMWPE, (c) UHMWPE-MWCNT, and (d) strain hardened UHMWPE-MWCNT.

TABLE 3: DSC test results.

\begin{tabular}{|c|c|c|c|c|c|c|}
\hline Samples & Percent crystallinity (\%) & Rate of crystallization (\%/min) & $T_{m}\left({ }^{\circ} \mathrm{C}\right)$ & $T_{0}\left({ }^{\circ} \mathrm{C}\right)$ & $T_{p}\left({ }^{\circ} \mathrm{C}\right)$ & $d T=T_{0}-T_{p}\left({ }^{\circ} \mathrm{C}\right)$ \\
\hline NeatUHMWPE & 33.5 & 3.4 & 131.73 & 120.58 & 112.82 & 7.76 \\
\hline UHMWPE (S.H) & 37.7 & 3.5 & 129.14 & 120.45 & 113.81 & 6.64 \\
\hline UHMWPE- MWCNT & 42.1 & 4.8 & 128.67 & 123.00 & 116.14 & 6.86 \\
\hline UHMWPE-MWCNT (S.H) & 48.2 & 4.9 & 127.25 & 121.71 & 115.66 & 6.05 \\
\hline
\end{tabular}

into crystals which can act as network junctions [31] and elongate as seen in Figure 6(b). SEM images of UHMWPEMWCNT samples at higher resolutions are shown in Figures 6(c) and 6(d). It is observed in Figure 6(c) that nanotubes are coated with a thick polymer layer. It is also seen that diameter of the polymer coated nanotube is around $270 \mathrm{~nm}$ which is much higher than that of the dispersed nanotubes.
This indicates significant polymer wetting of the nanotube surface. It was mentioned earlier that defects at nanotube surface are ideal sites for nucleation. UHMWPE, a crystalline polymer, can therefore aggregate on such nucleation sites. As nucleation occurs at multiple sites, a thick coating of polymer layer can form on the nanotube surface. These polymer coatings reduced the Van der Waal interactions between 


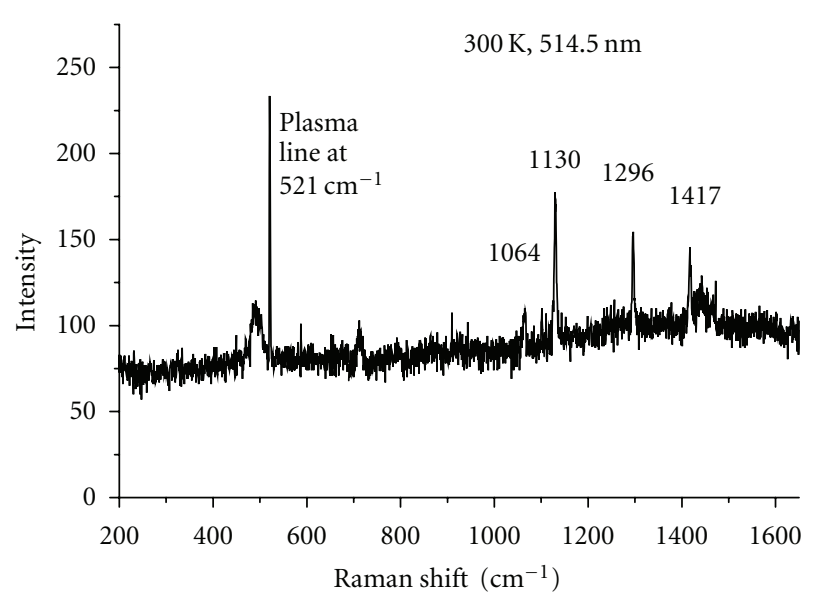

(a)

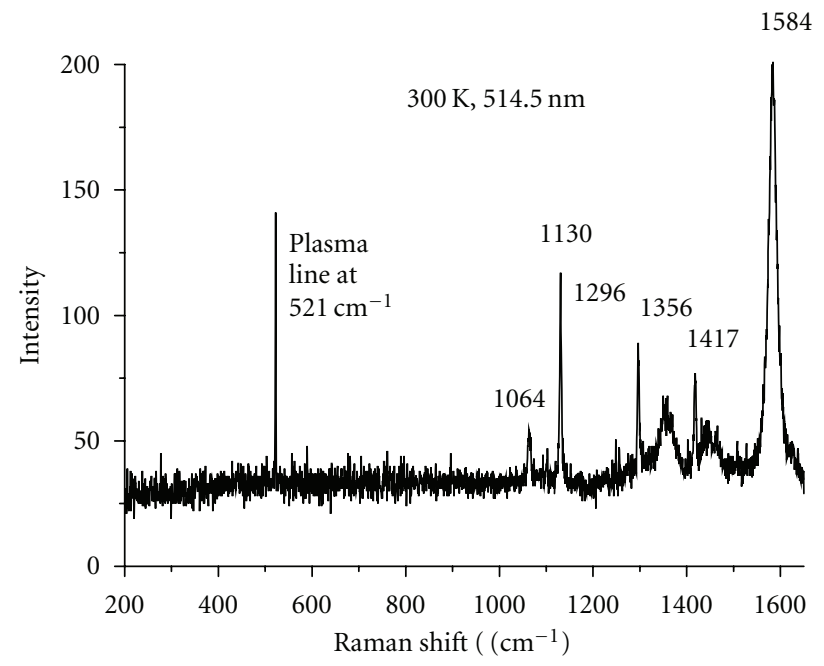

(c)

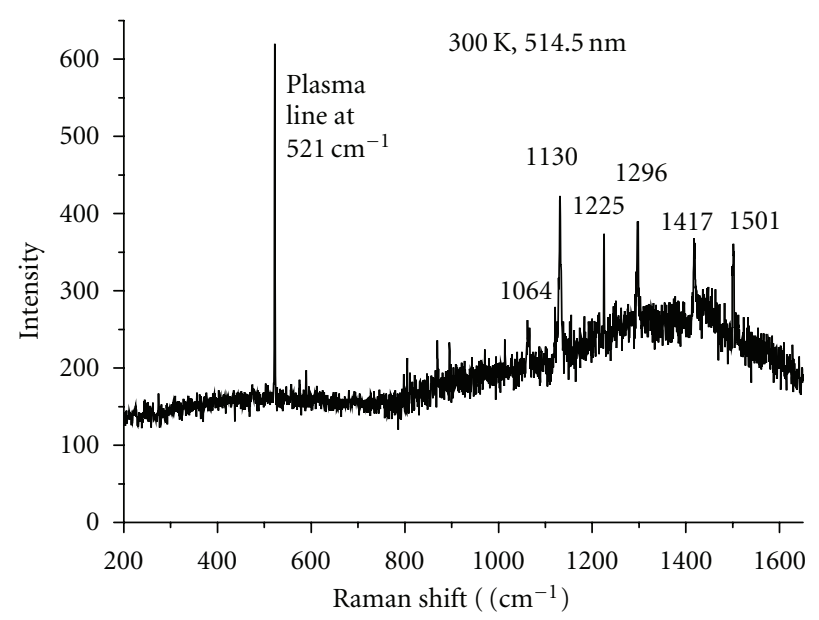

(b)

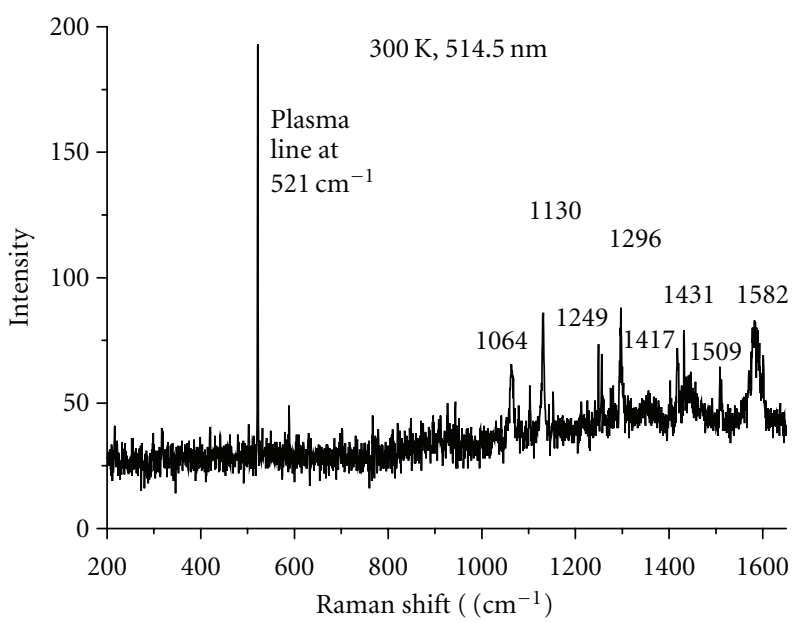

(d)

FIGURE 7: Raman spectrums of (a) neat UHMWPE, (b) UHMWPE after strain hardening, (c) UHMWPE-MWCNT, and (d) UHMWPEMWCNT after strain hardening.

the MWCNTs and prevented agglomeration of nanotubes inside the polymer matrix. Polymer coating of nanotubes have also been reported earlier [10,32]. Polymer coatings played a significant role in the interfacial load transfer mechanism. Large increase in strength in our case suggests an effective transfer due to such coating. When samples were strain hardened, interfacial coating also helped alignment of nanotubes as seen in Figure 6(d). Array of nanotubes are seen partially aligned in the loading direction. Higher values of strength and modulus seen in strain hardened UHMWPE-MWCNT samples are direct consequences of improved alignment and coating of nanotubes.

4.5. Raman Spectroscopy Tests. Raman spectroscopy has been proved to be an effective technique to characterize and study the deformation of polymer [33]. When polymers are deformed, the bonds in the molecules are strained and some of the frequencies of Raman bands are shifted to lower or higher wave numbers depending on the tension or compression in the molecular bonds. Raman spectra of individual filament were obtained using a T64000 spectrometer. As expected both asymmetric stretching mode $\left(1064 \mathrm{~cm}^{-1}\right)$ and symmetric stretching mode $\left(1130 \mathrm{~cm}^{-1}\right)$ of $\mathrm{C}-\mathrm{C}$ bonds for polyethylene [34-39] were observed in all samples (Figures $7(\mathrm{a})-7(\mathrm{~d}))$. With the addition of MWCNTs two more bands at $1356 \mathrm{~cm}^{-1}$ and at $1584 \mathrm{~cm}^{-1}$ appeared (Figure $7(\mathrm{c})$ ). These two bands are termed as $D$ and $G$ bands, respectively. $D$ band in the Raman spectra suggests presence of defect sites in nanotubes while $G$ band indicates stretching mode of C-C bonds [40-42]. When UHMWPE-MWCNT samples are strain hardened, $D$ and $G$ bands shift to $1431 \mathrm{~cm}^{-1}$, and $1582 \mathrm{~cm}^{-1}$, respectively (Figure $7(\mathrm{~d})$ ). It is observed that there is a positive shift in $D$ while a negative shift in $G$ bands. Positive shift in $D$ band is an indication of contraction which we believe is due to the lateral compression of nanotubes at the defect sites by the surrounding polymer. 
Such lateral compression of nanotubes is very much likely during the strain hardening process as they would tend to elongate. Elongation of nanotubes is also evidenced by further stretching of $\mathrm{C}-\mathrm{C}$ bonds as indicated by the negative shift in the $G$ band (Figure 7(d)).

Two additional bands at $1225 \mathrm{~cm}^{-1}$ and at $1501 \mathrm{~cm}^{-1}$ are also observed in neat UHMWPE samples when they are strain hardened (Figure 7(b)). These two bands belong to $\mathrm{CH}_{2}$ twisting and $\mathrm{CH}_{2}$ bending modes $[36,43]$. However in strain hardened UHMWPE-MWCNT samples, we observe a positive shift in both of these bands to $1249 \mathrm{~cm}^{-1}$ and $1509 \mathrm{~cm}^{-1}$, respectively (Figure $7(\mathrm{~d})$ ). This positive shift suggests a less or restricted twisting and bending of $\mathrm{CH}_{2}$ bonds due to the presence of nanotubes.

\section{Summary}

(1) A solution spinning methodology is presented to infuse nanotubes into a textile polymer (UHMWPE). The method has been used successfully to produce nanotube reinforced filaments

(2) Although the concentration of nanotubes was only at $2.0 \mathrm{wt} \%$, the improvement in mechanical properties was significant. Strength and modulus increased by $62 \%$ and $114 \%$, respectively.

(3) It is also shown that strain hardening effect is prominent in UHMWPE filaments. It is demonstrated that strength and modulus of neat UHMWPE filaments can be increased by more than one order of magnitude through strain hardening. If UHMWPE filaments are infused with MWCNTs, the improvement is even higher. For example, strength of neat UHMWPE increases from $61 \mathrm{MPa}$ to $1.9 \mathrm{GPa}$, while that of modulus increases from $238 \mathrm{Mpa}$ to $10.3 \mathrm{GPa}$.

(4) SEM micrographs have revealed that the alignment of nanotubes in the draw direction, and coating of nanotubes by the surrounding polymer were responsible for such improvement in mechanical properties. Polymer coating on the nanotubes surface formed an intimate interface with the polymer and allowed an effective load transfer especially when the nanotubes were aligned through strain hardening.

(5) Change in polymer morphology was also noticed. DSC results indicated an increase in crystallinity $(15 \%)$ and rate of crystallization (1.5\%/min). Melting temperature reduced by $4.5^{\circ} \mathrm{C}$ while crystallization temperature increased by $2.8^{\circ} \mathrm{C}$. These changes conform to earlier studies on nanophased filaments.

(6) Changes in vibrational frequencies were noticeable in Raman spectra especially after nanotubes reinforcement and strain hardening. A positive shift in the $D$ band suggested lateral compression of nanotubes while a negative shift in $G$ band indicated moderate stretching of $\mathrm{C}-\mathrm{C}$ bond in the nanotubes. Raman spectra further revealed that twisting and bending of $\mathrm{CH}_{2}$ bonds were restricted by nanotubes during strain hardening operations.

\section{Acknowledgment}

Authors would like to acknowledge support from the National Science Foundation (NSF) for this work through Grant no. HRD-976871.

\section{References}

[1] S. M. Kurtz, O. K. Muratoglu, M. Evans, and A. A. Edidin, "Advances in the processing, sterilization, and crosslinking of ultra-high molecular weight polyethylene for total joint arthroplasty," Biomaterials, vol. 20, no. 18, pp. 1659-1688, 1999.

[2] W. Wu and W. B. Black, "High-strength polyethylene," Polymer Engineering and Science, vol. 19, no. 16, pp. 1163-1169, 1979.

[3] H. Mahfuz, A. Adnan, V. K. Rangari, and S. Jeelani, "Manufacturing and characterization of carbon nanotube/polyethylene composites," International Journal of Nanoscience, vol. 4, no. 1, pp. 55-72, 2005.

[4] H. Mahfuz, A. Adnan, V. K. Rangari et al., "Enhancement of strength and stiffness of nylon 6 filaments through carbon nanotubes reinforcement," Applied Physics Letters, vol. 88, no. 8, Article ID 083119, 2006.

[5] S. Ruan, P. Gao, and T. X. Yu, "Ultra-strong gel-spun UHMWPE fibers reinforced using multiwalled carbon nanotubes," Polymer, vol. 47, no. 5, pp. 1604-1611, 2006.

[6] H. R. Brown, "Studies of orientation and structure of crazed matter in polystyrene. I. Optical measurements," Journal of Polymer Science: Polymer Physics Edition, vol. 17, no. 8, pp. 1417-1430, 1979.

[7] A. J. Kinloch and R. J. Young, Fracture Behaviour of Polymers, Elsevier Applied Science, London, UK, 1988.

[8] R. Hiss, S. Hobeika, C. Lynn, and G. Strobl, "Network stretching, slip processes, and fragmentation of crystallites during uniaxial drawing of polyethylene and related copolymers. A comparative study," Macromolecules, vol. 32, no. 13, pp. 43904403, 1999.

[9] C. Zhao, G. Hu, R. Justice et al., "Synthesis and characterization of multi-walled carbon nanotubes reinforced polyamide 6 via in situ polymerization," Polymer, vol. 46 , no. 14 , pp. $5125-$ 5132, 2005.

[10] B. McCarthy, J. N. Coleman, S. A. Curran et al., "Observation of site selective binding in a polymer nanotube composite," Journal of Materials Science Letters, vol. 19, no. 24, pp. 22392241, 2000.

[11] J. Smook and A. J. Pennings, "Suspension spinning of ultrahigh molecular weight polyethylene," Polymer Bulletin, vol. 10, no. 7-8, pp. 291-297, 1983.

[12] P. J. Lemstra, C. W. M. Bastiaansen, and H. E. H. Meijer, "Chain-extended flexible polymers," Die Angewandte Makromolekulare Chemie, vol. 145, no. 1, pp. 343-358, 1986.

[13] P. Smith and P. J. Lemstra, "Ultra-high-strength polyethylene filaments by solution spinning/drawing," Journal of Materials Science, vol. 15, no. 2, pp. 505-514, 1980.

[14] P. M. Pakhomov, A. Yu. Golikova, S. D. Khizhnyak et al., "The structure of high-strength ultrahigh-molecular-weight polyethylene fibres fabricated by the gel-spinning method," Fibre Chemistry, vol. 38, no. 3, pp. 200-206, 2006.

[15] Y. Gogotsi, Nanomaterials Handbook, CRC Press, Tailor \& Francis, Boca Raton, Fla, USA, 2006.

[16] H. Mahfuz, M. Khan, and Th. Leventouri, "Reinforcement of Low Density Polyethylene (LDPE) with CNT and Ultra High Molecular Weight Polyethylene (UHMWPE): a systematic 
approach to enhance strength, modulus and toughness," in Proceedings of the 13th US-Japan Conference on Composite Materials, Tokyo, Japan, June 2008.

[17] M. R. Khan, H. Mahfuz, Th. Leventouri, V. K. Rangari, and A. Kyriacou, "Enhancing toughness of low-density polyethylene filaments through infusion of multiwalled carbon nanotubes and ultrahigh molecular weight polyethylene," Polymer Engineering \& Science, vol. 51, no. 4, pp. 654-662, 2011.

[18] H. Mahfuz, M. M. Hasan, V. K. Rangari, and S. Jeelani, "Reinforcement of nylon-6 filaments with $\mathrm{SiO}_{2}$ nanoparticles and comparison of young's modulus with theoretical bounds," Macromolecular Materials and Engineering, vol. 292, no. 4, pp. 437-444, 2007.

[19] H. Mahfuz, M. Hasan, V. Dhanak et al., "Reinforcement of nylon 6 with functionalized silica nanoparticles for enhanced tensile strength and modulus," Nanotechnology, vol. 19, no. 44, Article ID 445702, 2008.

[20] N. E. Dowling, Mechanical Behavior of Meterials, Pearson, Prentice Hall, Upper Saddle River, NJ, USA, 2007.

[21] Y. Hu, O. A. Shenderova, Z. Hu, C. W. Padgett, and D. W. Brenner, "Carbon nanostructures for advanced composites," Reports on Progress in Physics, vol. 69, no. 6, pp. 1847-1895, 2006.

[22] A. Peterlin, "Crystalline character in polymers," Journal of Polymer Science. Part C, vol. 9, no. 1, pp. 61-89, 1965.

[23] A. Peterlin, "Molecular model of drawing polyethylene and polypropylene," Journal of Materials Science, vol. 6, no. 6, pp. 490-508, 1971.

[24] A. Peterlin, "Plastic deformation of polyethylene. Mechanism and Properties," Journal of Polymer Science. Part C, vol. 15, no. 1, pp. 427-443, 1967.

[25] A. Peterlin, in Structure and Properties of Oriented Polymers, 2nd Ed., I. M. Ward, Ed., Chapman \& Hall, 2-6 Boundary Row, London, UK, 1997.

[26] S. L. Ruan, P. Gao, X. G. Yang, and T. X. Yu, “Toughening high performance ultrahigh molecular weight polyethylene using multiwalled carbon nanotubes," Polymer, vol. 44, no. 19, pp. 5643-5654, 2003

[27] M. Khan, H. Mahfuz, and Th. Leventouri, "Investigation of infusion of Ultra High Molecular Weight Polyethylene (UHMWPE) and Carbon Nanotube (CNT) into Low Density Polyethylene (LDPE) filaments," in Proceedings of the SAMPE Fall Technical Conference, Memphis, Tenn, USA, September 2008.

[28] N. C. Parasnis and K. Ramani, "Non-isothermal crystallization of UHMWPE," Journal of Thermal Analysis and Calorimetry, vol. 55, no. 3, pp. 709-719, 1999.

[29] F. G. Shi, "Size dependent thermal vibrations and melting in nanocrystals," Journal of Materials Research, vol. 9, no. 5, pp. 1307-1313, 1994.

[30] T. Castro, R. Reifenberger, E. Choi, and R. P. Andres, "Sizedependent melting temperature of individual nanometersized metallic clusters," Physical Review B, vol. 42, no. 13, pp. 8548-8556, 1990.

[31] D. R. Salem, Structure Formation in Polymeric Fibers, Hanser Gardner Publications, Munich, Germany, 2001.

[32] W. Ding, A. Eitan, F. T. Fisher et al., "Direct observation of polymer sheathing in carbon nanotube-polycarbonate composites," Nano Letters, vol. 3, no. 11, pp. 1593-1597, 2003.

[33] W. F. Wong and R. J. Young, "Analysis of the deformation of gel-spun polyethylene fibres using Raman spectroscopy," Journal of Materials Science, vol. 29, no. 2, pp. 510-519, 1994.

[34] K. Prasad and D. T. Grubb, "Direct observation of taut tie molecules in high-strength polyethylene fibers by Raman spectroscopy," Journal of Polymer Science. Part B, vol. 27, no. 2, pp. 381-403, 1989.

[35] J. Kip, M. C. P. Van, and R. J. Meier, "Molecular deformation of high-modulus polyethylene fibers studied by micro-raman spectroscopy," Journal of Polymer Science. Part B, vol. 29, no. 1, pp. 99-108, 1991.

[36] G. Socrates, Infrared and Raman Characteristic Group Frequencies: Tables and Charts, John Wiley \& Sons, West Sussex, UK, 3rd edition, 2001.

[37] J. A. H. M. Moonen, W. Roovers, R. Meier, and B. Kip, “Crystal and molecular deformation in strained high-performance polyethylene fibers studied by wide-angle X-ray scattering and Raman spectroscopy," Journal of Polymer Science. Part B, vol. 30, no. 4, pp. 361-372, 1992.

[38] D. T. Grubb and Z. F. Li, "Molecular stress distribution and creep of high-modulus polyethylene fibres," Polymer, vol. 33, no. 12, pp. 2587-2597, 1992.

[39] C. A. Cooper, R. J. Young, and M. Halsall, "Investigation into the deformation of carbon nanotubes and their composites through the use of Raman spectroscopy," Composites. Part A, vol. 32, no. 3-4, pp. 401-411, 2001.

[40] R. J. Nemanich and S. A. Solin, "Observation of an anomolously sharp feature in the 2nd order Raman spectrum of graphite," Solid State Communications, vol. 23, no. 7, pp. 417-420, 1977.

[41] R. J. Nemanich and S. A. Solin, "First- and second-order Raman scattering from finite-size crystals of graphite," Physical Review B, vol. 20, no. 2, pp. 392-401, 1979.

[42] Y. Huang and R. J. Young, "Microstructure and mechanical properties of pitch-based carbon fibres," Journal of Materials Science, vol. 29, no. 15, pp. 4027-4036, 1994.

[43] B. H. Stuart, "Polymer crystallinity studied using Raman spectroscopy," Vibrational Spectroscopy, vol. 10, no. 2, pp. 79$87,1996$. 

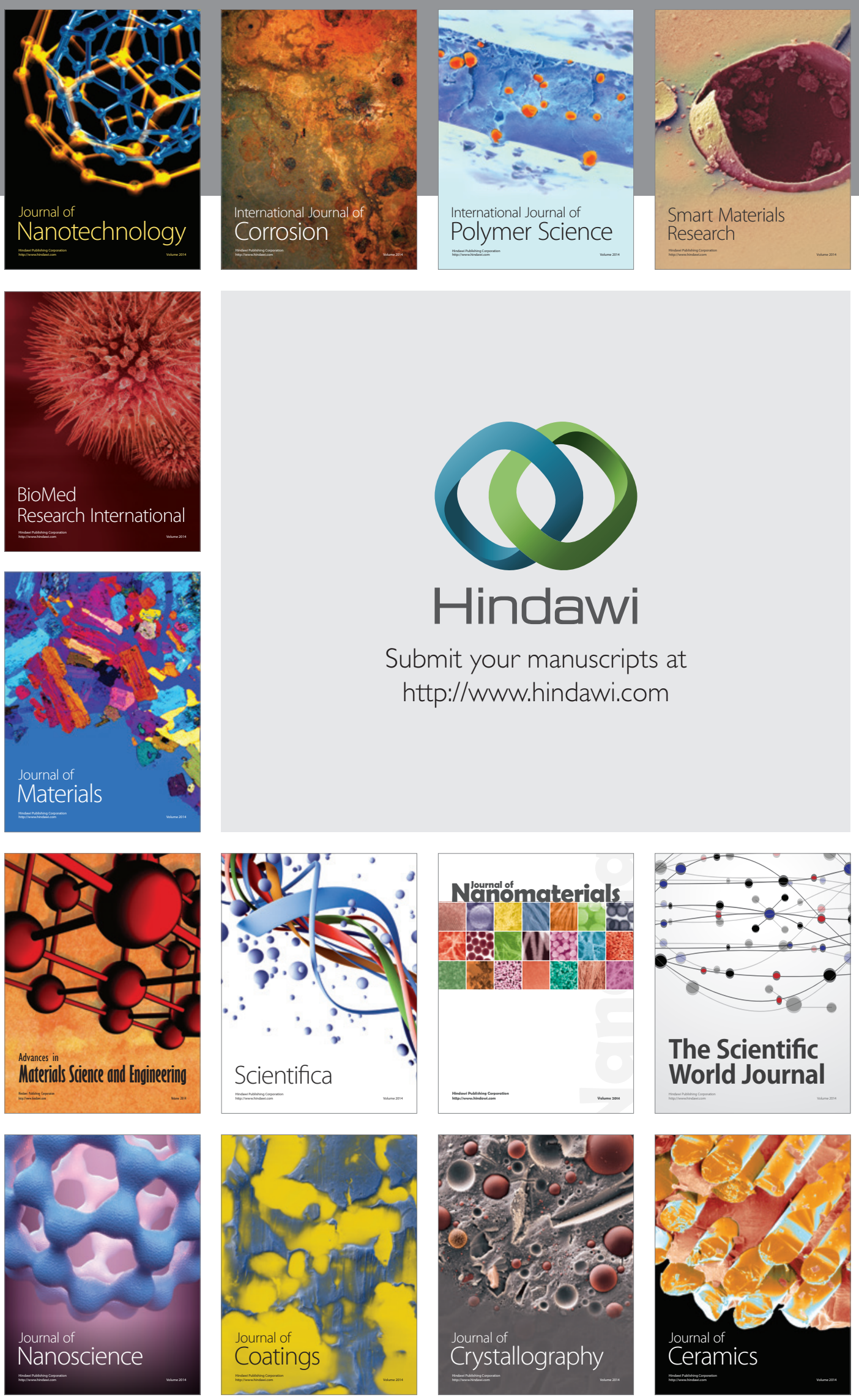

The Scientific World Journal

Submit your manuscripts at

http://www.hindawi.com

\section{World Journal}

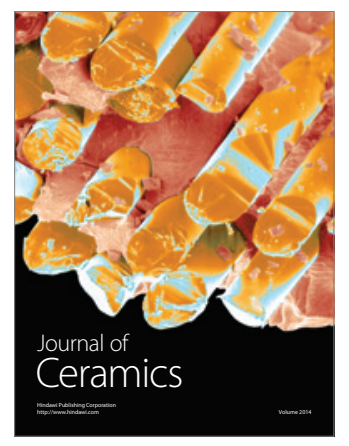

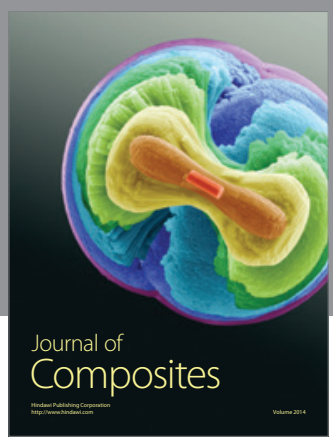
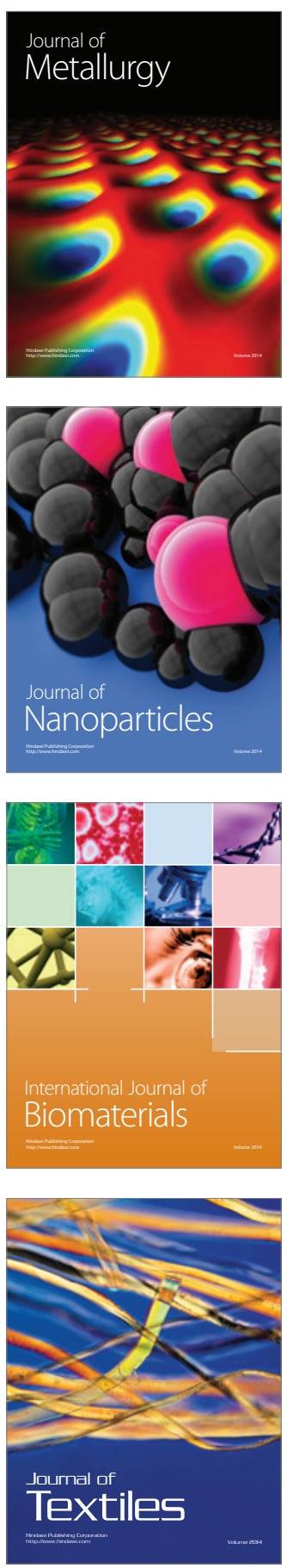